\title{
IDENTIFICATION, ISOLATION AND OPTIMIZATION OF ANTIFUNGAL METABOLITES FROM THE STREPTOMYCES MALACHITOFUSCUS CTF9
}

\author{
Imran Sajid $^{1,2}$; Khaled A. Shaaban ${ }^{2}$; Shahida Hasnain ${ }^{1} *$ \\ ${ }^{1}$ Department of Microbiology and Molecular Genetics, University of the Punjab, Quaid-e-Azam Campus, Lahore 54590, Pakistan; \\ 2Institute of Organic and Biomolecular Chemistry, University of Göttingen, Tammannstrasse 2, D-37077 Göttingen
}

Submitted: September 04, 2010; Returned to authors for corrections: October 19, 2010; Approved: January $13,2011$.

\begin{abstract}
An indigenous Streptomyces isolate CTF9, exhibiting promising antifungal activity against Mucor miehei and Candida albicans in pre-screening studies, was investigated by cultivation in a 50-L fermenter and by subsequent isolation, purification, and structure elucidation of the active metabolites. Based on the morphological, biochemical, and physiological characterization, as well as the 16S rRNA gene sequence, the isolate CTF9 was identified as Streptomyces malachitofuscus. Using a series of chromatographic techniques, two pure compounds were isolated from the obtained extracts after the fermentation of the isolate CTF9. The isolated compounds were identified as phenylacetic acid and indolyl-3-lactic acid by mass spectrometry (MS) and NMR analysis. The culture optimization studies revealed that the isolate CTF9 can use a variety of low-cost carbon and nitrogen sources to generate the maximum quantity of industrially important metabolites at an elevated temperature of $35^{\circ} \mathrm{C}$ and at a $\mathrm{pH} 7.8$.
\end{abstract}

Key words: Phenylacetic acid, Indolyl-3-lactic acid, indigenous Streptomyces sp. CTF9

\section{INTRODUCTION}

Actinomycetes are the major producers of pharmaceuticals, agricultural pesticides, and veterinary medicine because of their ability to produce antibiotics. Among the actinomycetes, the genus Streptomyces has continued to provide a larger number and wider variety of new antibiotics than any other genus, suggesting that a substantial number of Streptomyces species or strains with novel antibiotic productivity exist in nature. These bacteria produce about $75 \%$ of commercially and medically useful antibiotics $(3,18)$. Moreover, approximately $60 \%$ of the antibiotics developed for agricultural use are isolated from Streptomyces spp. (26). Fungal pathogens have been the major culprits for significant agricultural losses due to the plant diseases that they cause; they are also the causal agents of many medically important diseases. Therefore, currently, there is an immense need for antifungal agents. Several members of the streptomycetes family have been reported as potential biocontrol agents and as the potent producers of antifungal compounds (16, 24), indicating that these filamentous bacteria possess a vast potential for producing antifungal metabolites. In search for antifungal agents, Streptomyces strains have been isolated from various types of soils, including rice paddy, lake mud and

*Corresponding Author. Mailing address: Department of Microbiology and Molecular Genetics, University of the Punjab, Quaid-e-Azam Campus, Lahore 54590, Pakistan.; Tel.: 0092-42-9238530, Fax: 0092-42-9230481.; E-mail: shahida@ mmg.pu.edu.pk 
water, deciduous forest, tropical forest, wasteland, and cave soils $(6,8,11,23,25,29)$. Their natural habitat soil is nutritionally, biologically and physically complex and variable, demanding their fast adaptation. As a consequence, they are able to perform a broad range of metabolic processes and to produce an immense diversity of bioactive secondary metabolites.

In our search for bioactive secondary metabolites from indigenous Streptomyces, more than 100 active Streptomyces strains were isolated from the soil samples collected from saline agricultural farmlands in our area (Punjab, Pakistan) and were screened for antimicrobial activity and the metabolites that they produced (21). The isolate Streptomyces sp. CTF9 exhibited promising antifungal activity against Candida albicans and Mucor miehei, suggesting it as a promising strain to be further evaluated by preparative screening for the isolation, purification and structure elucidation of active metabolites. The microscopic, morphological, biochemical and physiological characterization strongly suggests that the isolate belongs to the genus Streptomyces. Its $16 \mathrm{~S}$ rRNA gene sequence shows a maximum similarity (99\%) to Streptomyces malachitofuscus; the 1426-bp sequence of the 16S rRNA gene of the isolate Streptomyces sp. CTF9 is available at GenBank, with the accession number of EU294138. Here, we reported the fermentation, isolation, purification, and structure elucidation of the active antifungal metabolites produced by the isolate Streptomyces sp. CTF9, along with the optimization of the production of these metabolites under different media compositions and culture conditions.

\section{MATERIALS AND METHODS}

\section{Cultivation of the Strain Streptomyces sp. CTF9}

The Streptomyces sp. CTF9 was cultivated in a $50-\mathrm{L}$ fermenter (Biostat $U$ ) (working volume: $30 \mathrm{~L}$ ) using $\mathrm{M}_{2}$ medium (malt extract $10 \mathrm{~g}$, yeast extract $4 \mathrm{~g}$, and glucose $4 \mathrm{~g}$ in $1 \mathrm{~L}$ of distilled water). The fermenter was filled with $27 \mathrm{~L}$ of water mixed with the corresponding quantities of $\mathrm{M}_{2}$ medium components. The medium was sterilized by keeping the fermenter in the sterilization mode for 30 minutes at $121^{\circ} \mathrm{C}$. After the air supply was turned on, a stirring motor and water circulation pumps were subsequently turned on. The acid $(2 \mathrm{~N}$ $\mathrm{HCl})$, base $(2 \mathrm{~N} \mathrm{NaOH})$ and antifoam $(1 \% \mathrm{Niax} / 70 \%$ ethanol) were filled in their respective jars and were connected to the fermenter. The $\mathrm{pH}$ electrode was sterilized using $70 \%$ ethanol and was adjusted The preculture was prepared by inoculating the isolate CTF9 from well-grown plates into $12 \times 250 \mathrm{~mL}$ of $\mathrm{M}_{2}$ medium in 1-L Erlenmeyer flasks (total volume: $3 \mathrm{~L}$ ). The flasks were incubated at $28^{\circ} \mathrm{C}$ on a linear shaker for 4 days; $10 \%$ of the preculture was used to inoculate the fermenter. The growth parameters were adjusted as follows: temperature $28^{\circ} \mathrm{C}$, $\mathrm{pH} 6.5 \pm 1.5$, and aeration $1.8 \mathrm{~m}^{3} / \mathrm{h}$. Fermentation was conducted for 5 days.

\section{Extraction and purification of the active compounds}

After harvesting the dark brown culture, the broth was filtered over celite using a filter press (Schenk Niro 212 B40) to separate the mycelium from the liquid phase. The mycelial cake was extracted using ethyl acetate (3 times) and acetone (1 time). The water phase was extracted by adsorption on Amberlite XAD-16 resin in a large-size glass column $(100 \times 5$ $\mathrm{cm}$ ) and was eluted with methanol. The solvents (ethyl acetate, acetone, and methanol) containing bioactive metabolites were dried using a rotary evaporator (Rotavapor R152) yielding 5.64 $\mathrm{g}$ of crude extracts.

Both mycelia and water-phase extracts were then collected, based on the characterization using TLC. The crude extract (5.64 g) was fractionated on a silica gel column (Kieselgel 60, $70 \sim 230$ mesh, Merck, Darmstadt, Germany, 30 g, $1.5 \times 50$ cm) using a $\mathrm{CH}_{2} \mathrm{Cl}_{2}$ : $\mathrm{MeOH}$ gradient $(0,5,10,20,30,40$, and $50 \%, \mathrm{vol} / \mathrm{vol})$ and was divided into two fractions. Fraction I was characterized as fat (1.85 g) using TLC and spraying reagents. Fraction II was further purified by silica gel column chromatography $(1.2 \times 30 \mathrm{~cm}$, packed with $15 \mathrm{~g}$ of silica gel $)$, 
preparative TLC and Sephadex LH-20 (25 100 mesh, Pharmacia Fine Chemicals, Uppsala, Sweden) in a column (86 $\times 2.0 \mathrm{~cm}$ ) and was eluted with $\mathrm{CH}_{2} \mathrm{Cl}_{2}: 40 \% \mathrm{MeOH}$, yielding colorless solids of phenylacetic acid (1;25.7 mg) and indolyl3-lactic acid (3; $12.8 \mathrm{mg})$.

\section{Structure determination of the purified compounds}

Mass spectra: The purified fractions were analyzed by EI MS at $70 \mathrm{eV}$ with Varian MAT 731, Varian 311A, AMD-402, ESI MS using a Quattro Triple Quadruple mass spectrometer Finigan MAT-Incos 50, ESI-MS LCQ (Finnigan) and ESIHRMS using perfluorokerosene as standard.

Nuclear Magnetic Resonance (NMR) Spectroscopy: ${ }^{1} \mathrm{H}$ NMR spectra were measured by Varian Unity $300(300 \mathrm{MHz})$, Bruker AMX 300 (300 MHz), and Varian Inova 500 (499.8 $\mathrm{MHz}$ ). Coupling constants $(J)$ in $\mathrm{Hz} .{ }^{13} \mathrm{C}$ NMR spectra were measured by Varian Unity $300(75.5 \mathrm{MHz})$ and Varian Inova $500(125.7 \mathrm{MHz})$. Chemical shifts $(\delta)$ were measured, relative to the internal control tetramethylsilane.

\section{Production optimization}

The six different media $A, B, C, D, E$ and $F$ used in the study were as follows: A: malt extract $10 \mathrm{~g}$, yeast extract $4 \mathrm{~g}$, and glucose $4 \mathrm{~g}$ in $1 \mathrm{~L}$ of $\mathrm{DH}_{2} \mathrm{O}$, B: soya been fat $20 \mathrm{~g}$ and mannitol $20 \mathrm{~g}$ in $1 \mathrm{~L}$ of $\mathrm{DH}_{2} \mathrm{O}, \mathrm{C}$ : glucose anhydrous $10 \mathrm{~g}$, peptone $2 \mathrm{~g}$, yeast extract $1 \mathrm{~g}$, and meat extract $1 \mathrm{~g}$ in $1 \mathrm{~L}$ of $\mathrm{DH}_{2} \mathrm{O}$, D: yeast extract $40 \mathrm{~g}$, glucose $5 \mathrm{~g}$, and $\mathrm{CaCl}_{2} 45 \mathrm{~g}$ in $1 \mathrm{~L}$ of $\mathrm{DH}_{2} \mathrm{O}$, E: trypton $10 \mathrm{~g}$, yeast extract $5 \mathrm{~g}, \mathrm{NaCl} 10 \mathrm{~g}$, and glucose $5 \mathrm{~g}$ in $1 \mathrm{~L}$ of $\mathrm{DH}_{2} \mathrm{O}, \mathrm{F}$ : glucose $21 \mathrm{~g}$, fish flour $5 \mathrm{~g}$, flour $10 \mathrm{~g}, \mathrm{MgSO}_{4} 0.5 \mathrm{~g}, \mathrm{NaCl} 1 \mathrm{~g}, \mathrm{CaCl}_{2} 0.5 \mathrm{~g}$, and trace elements $10 \mathrm{ml}$ in $1 \mathrm{~L}$ of $\mathrm{DH}_{2} \mathrm{O}$, (trace element stock solution: $\mathrm{FeSO}_{4} 0.2 \mathrm{~g}, \mathrm{COCl}_{2} 0.04 \mathrm{~g}, \mathrm{CaCl}_{2} 0.04 \mathrm{~g}$, manganese(II) chloride $0.04 \mathrm{~g}$, zinc sulphate $0.08 \mathrm{~g}$, and sodium borate $0.08 \mathrm{~g}$ in $1 \mathrm{~L}$ of $\mathrm{DH}_{2} \mathrm{O}$ ). In addition to different media compositions, the following four sets of culture conditions were applied: $\mathrm{CC} 1$ : $\mathrm{pH} 6.5$, incubation temperature of $28^{\circ} \mathrm{C}$, shaking at 95 rpm, for 7 days. $\mathrm{CC} 2$ : $\mathrm{pH} 6.5$, incubation temperature of $35^{\circ} \mathrm{C}$,

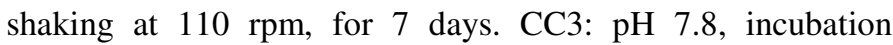
temperature of $28^{\circ} \mathrm{C}$, shaking at $95 \mathrm{rpm}$, for 7 days. $\mathrm{CC} 4: \mathrm{pH}$ 7.8 , incubation temperature of $35^{\circ} \mathrm{C}$, shaking at $110 \mathrm{rpm}$, for 7 days.

For each of the six media, $3 \mathrm{~L}$ were prepared and dispensed into 12 1-L flasks (12 x $250 \mathrm{~mL}$ culture broth). The flasks were grouped according to the proposed culture conditions; the $\mathrm{pH}$ in each flask was individually adjusted, and the flasks were sterilized by autoclaving and were inoculated with Streptomyces sp. CTF9 from well-grown plates. The inoculated flasks were incubated on linear shakers under the proposed culture conditions ( $\mathrm{CC} 1, \mathrm{CC} 2, \mathrm{CC} 3$ and $\mathrm{CC} 4)$. The strains were harvested after five days, the culture broth in each flask was freeze dried (Christ Alpha 2-4 D) and was individually extracted $(3 \mathrm{x})$ with ethyl acetate. Ethyl acetate was evaporated on a rotary evaporator (Heidolph Laborota 4000), and the crude extracts were obtained. The crude extracts were weighed to determine the quantity of metabolites produced under different cultural conditions. Subsequently, the crude extracts were individually tested against the test organisms Candida albicans and Mucor miehei to determine the quantity of the active antifungal metabolites per unit volume of each extract. The results were statistically analyzed using the analysis of variance (ANOVA) test (Duncan's multiple range test) by SPSS version $10(\mathrm{P}=0.001)$.

\section{RESULTS}

\section{Purification and structure elucidation of the active compounds}

The bulk fermentation was performed in a 50-L fermenter (Biostat $\mathrm{U}$ ) (working volume: $30 \mathrm{~L}$ ) using $\mathrm{M}_{2}$ medium. After harvesting, cell separation and solvent extraction, $5.64 \mathrm{~g}$ of the crude extract was obtained from both the mycelium and the liquid phase. The components of the crude extract were purified using silica gel column, preparative TLC and gel exclusion chromatography, yielding two pure compounds 
identified as phenylacetic acid and indolyl-3-lactic acid by ${ }^{1} \mathrm{H}$, ${ }^{13} \mathrm{C}$ NMR and mass spectrometry and by comparison to the published data.

\section{Phenylacetic acid (1)}

Compound 1 was isolated as a colorless, UV-absorbing solid and stained yellow on TLC by anisaldehyde/sulphuric acid spraying reagent. According to its chromatographic properties and spectroscopic data, compound 1 was identified as phenylacetic acid. The result was further confirmed by searching in AntiBase (14) and by comparing its MS and NMR data to those of an authentic sample (19). $p$ Hydroxyphenylacetic acid (2) and phenylacetic acid (1) were isolated from Taraxacum roots as natural products, by Power and Browning (20) and as fungal metabolites from Ophiostoma crassivaginata (2). Phenyl acetic acid is widespread in higher plants, fungi, e.g., Aspergillus niger (19), and bacteria. In microbial antibiotic production, compound 1 was added to the culture of Penicillium sp. to increase the production of penicillin $\mathrm{G}$ (parasticin) $(9,10)$.<smiles>[R]c1ccc(CC(=O)O)cc1</smiles>

$$
1: \mathbf{R}=\mathbf{H} ; 2: \mathbf{R}=\mathbf{O H}
$$

Phenylacetic acid (1): Colorless solid (25.7 mg), UVabsorbing, stained yellow by the anisaldehyde/sulphuric acid spraying reagent. $-R_{\mathrm{f}}=0.29\left(\mathrm{CH}_{2} \mathrm{Cl}_{2} / 3 \% \mathrm{MeOH}\right) .-{ }^{1} \mathrm{H} \mathrm{NMR}$ $\left(300 \mathrm{MHz}, \mathrm{CDCl}_{3}\right): \delta=9.50$ (brs, $\left.1 \mathrm{H}, \mathrm{OH}\right), 7.30-7.20(\mathrm{~m}, 5 \mathrm{H}$, Ar-H), 3.62 (s, 2H, $\mathrm{CH}_{2}$ ) (Figure 1a). - ${ }^{1} \mathrm{H}$ NMR (300 MHz, Acetone- $d_{6}$ ): $\delta=10.80$ (brs, $\left.1 \mathrm{H}, \mathrm{OH}\right), 7.50-7.30$ (m, $5 \mathrm{H}, \mathrm{Ar}-$ $\mathrm{H}$ ), $3.72\left(\mathrm{~s}, 2 \mathrm{H}, \mathrm{CH}_{2}\right.$ ) (Figure 1b). $-{ }^{13} \mathrm{C} \mathrm{NMR}(50 \mathrm{MHz}$, $\left.\mathrm{CDCl}_{3}\right): \delta=178.3(\mathrm{CO}), 133.2\left(\mathrm{C}_{\mathrm{q}}\right), 129.3(2 \mathrm{CH}), 128.6$ $(2 \mathrm{CH}), 127.3(\mathrm{CH}), 41.1\left(\mathrm{CH}_{2}\right)$ (Figure 2). - EI MS (70 eV): $m / z(\%)=136\left([\mathrm{M}]^{+}, 32\right), 91(100), 65(12)$ (Figure 3)

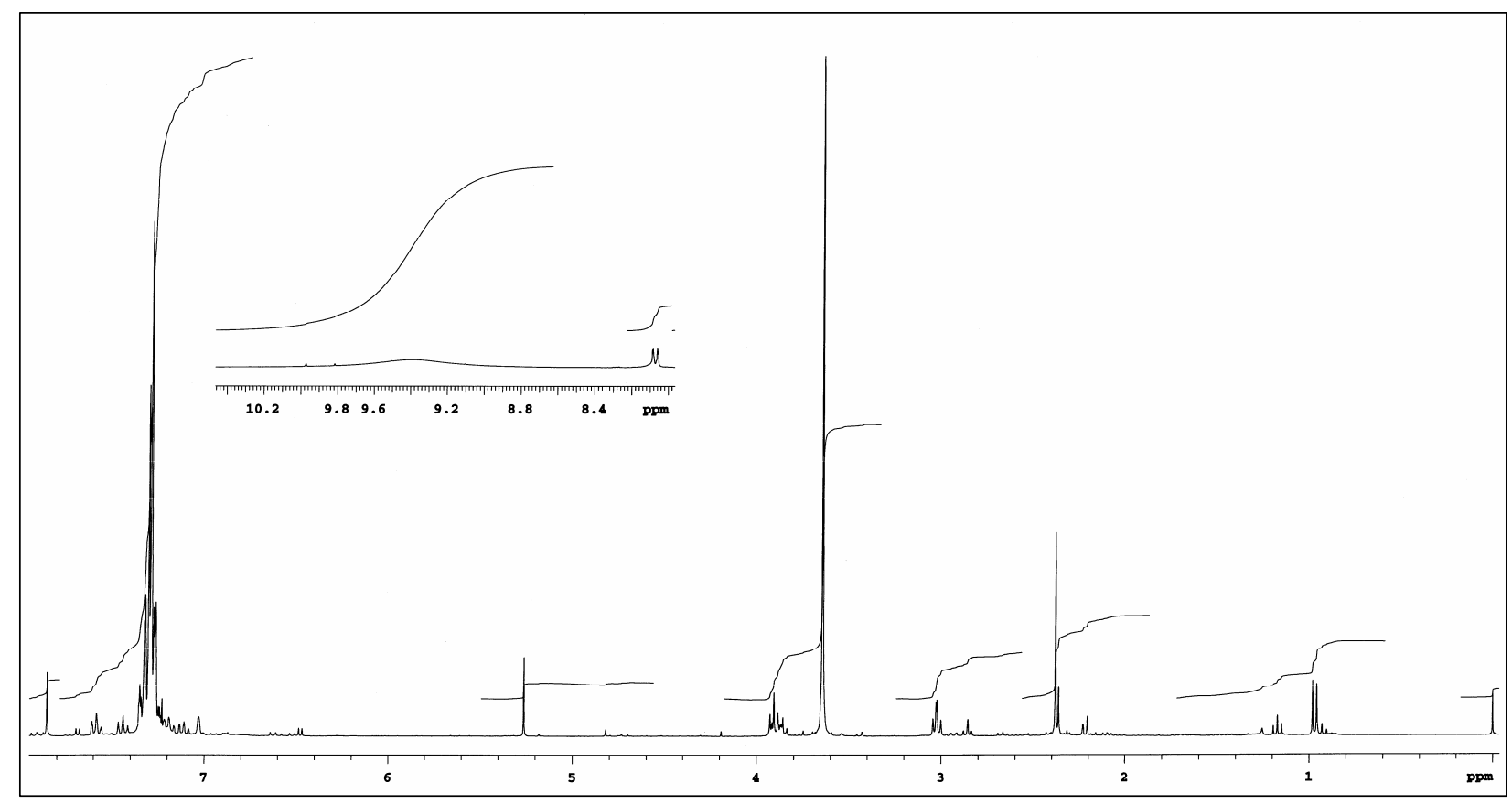

Figure 1a. ${ }^{1} \mathrm{H} \mathrm{NMR}\left(\mathrm{CDCl}_{3}, 300 \mathrm{MHz}\right)$ of phenylacetic acid 


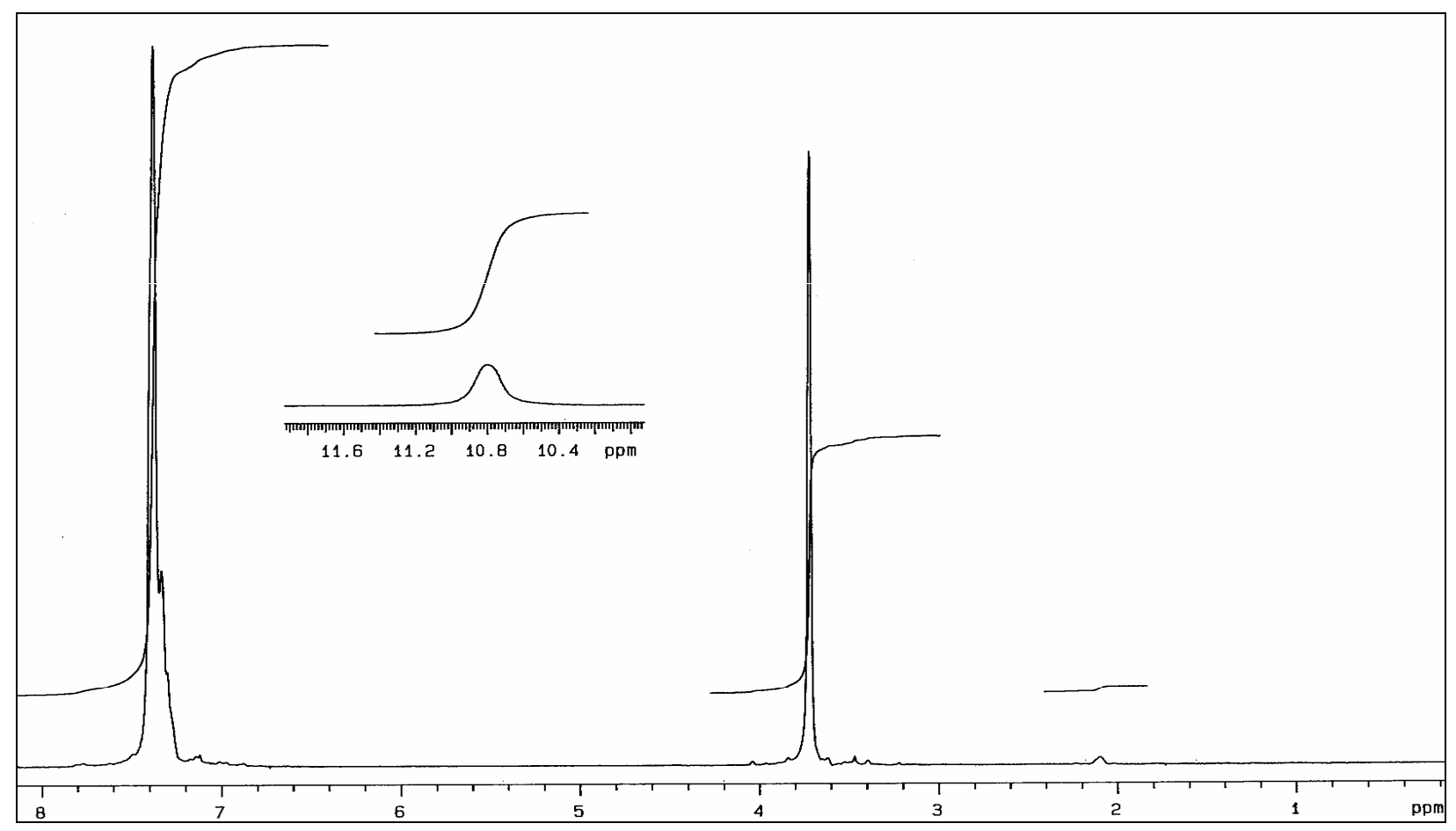

Figure 1b. ${ }^{1} \mathrm{H}$ NMR (Acetone- $d_{6}, 300 \mathrm{MHz}$ ) of phenylacetic acid

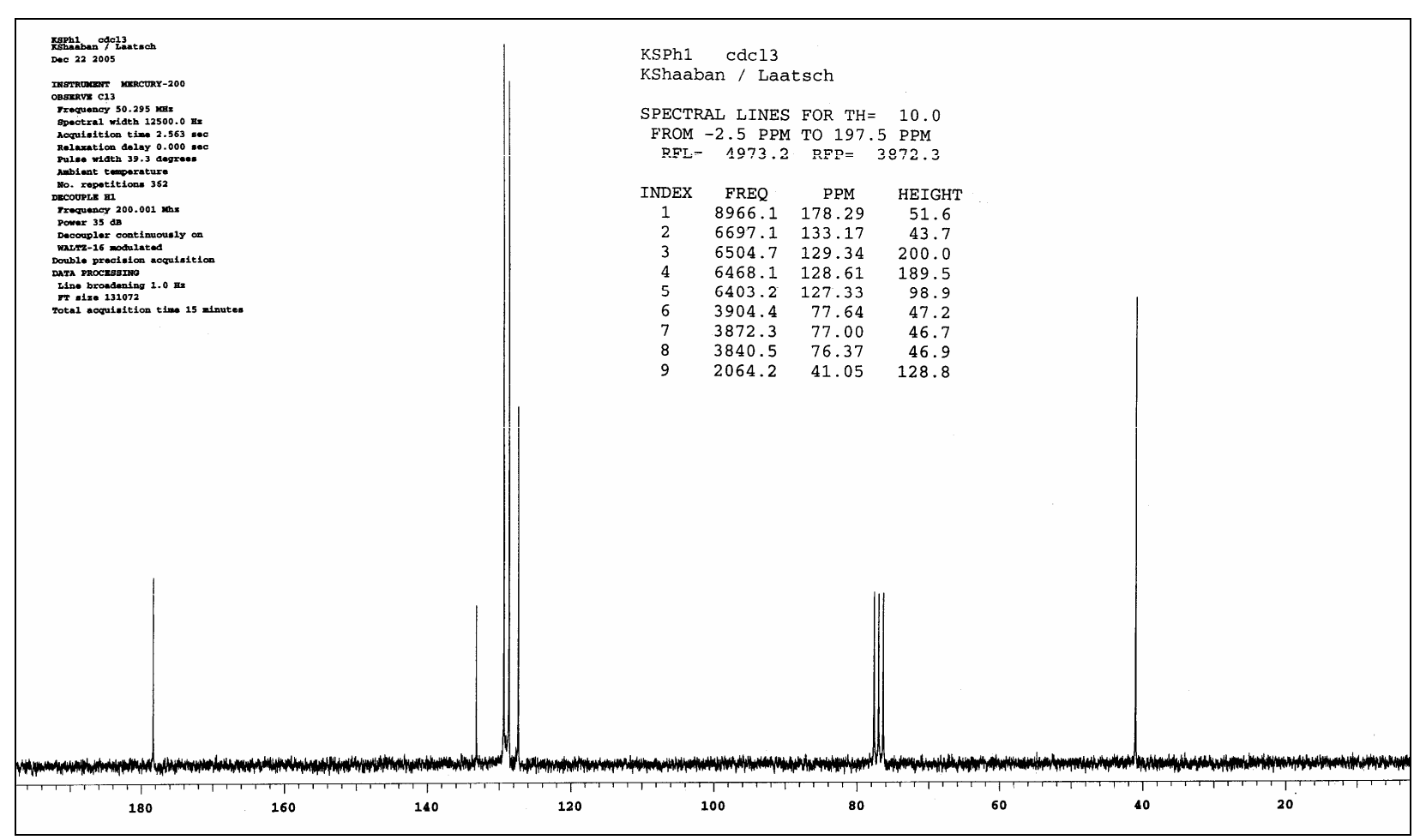

Figure 2. ${ }^{13} \mathrm{C} \mathrm{NMR}\left(\mathrm{CDCl}_{3}, 50 \mathrm{MHz}\right)$ of phenylacetic acid 


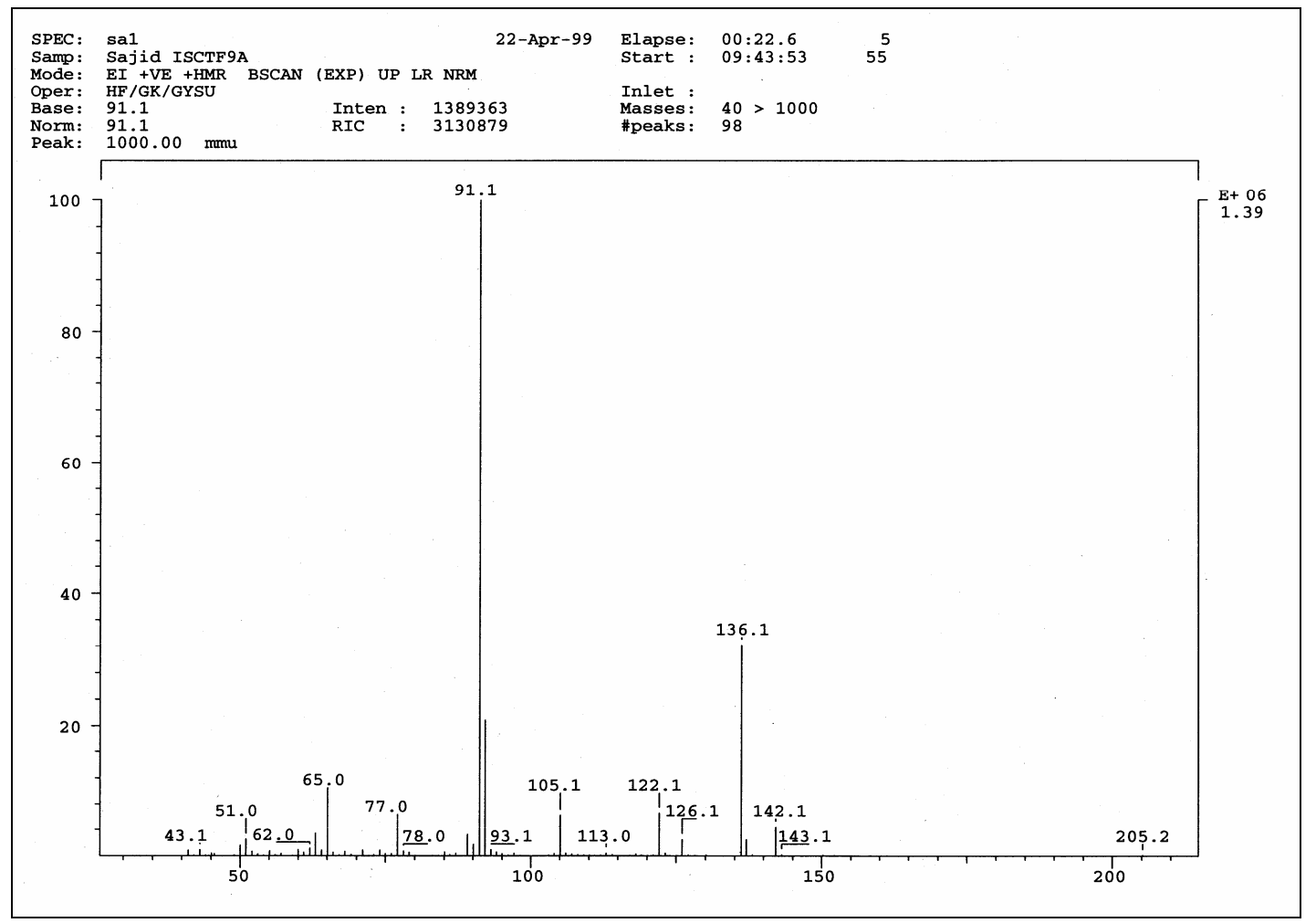

Figure 3. EI mass spectra of phenylacetic acid

\section{Indolyl-3-lactic acid (3)}

Compound 3 was isolated as a colorless, UV-absorbing solid and stained violet on TLC by anisaldehyde/sulphuric acid. The ${ }^{1} \mathrm{H}$ NMR spectrum of compound 3 exhibited two broad $1 \mathrm{H}$ singlet's of acidic protons at $\delta 10.75$ and 8.31. In addition, five aromatic protons distinctive for a 3-substituted indole moiety were observed, four of which at $\delta 7.72(\mathrm{dd}), 7.38$ (dd), $\delta 7.20(\mathrm{td})$, and 7.10 (td) were characteristic for a 1,2disubstituted aromatic ring. The fifth proton at $\delta 7.11$ showed a small long-range coupling constant $\left({ }^{3} J=0.8 \mathrm{~Hz}\right)$. In the aliphatic region at $\delta 4.55$, a dd signal of an oxygenated methine was displayed, forming an $\mathrm{ABX}$ system with a methylene group at $\delta 3.36$ and $\delta 3.20$, possibly adjacent to a $s p^{2}$ carbon.

The EI mass spectrum fixed the molecular weight of 3 as 205 Dalton. Furthermore, the mass ion $(\mathrm{m} / \mathrm{z} 205)$ was fragmented, giving a base peak at $m / z$ 130, characteristic for an indolyl-3-methylene ion. This result confirmed the presence of a hydroxy acetic acid fragment ( $\mathrm{HO}-\mathrm{CH}-\mathrm{COOH})$ and, hence, a hydroxypropionic acid residue at the position 3 of the indole skeleton. A search in AntiBase using the spectroscopic data resulted in indolyl-3-lactic acid (3) as the only matched structure. This identification was confirmed by comparing the data to the authentic spectra (13). Compound 3 is frequently found in bacteria, fungi and yeast (14) and exhibits activity against Candida albicans.<smiles>O=C(O)C(O)Cc1c[nH]c2ccccc12</smiles>

3 
<smiles>OCCc1c[nH]c2[c]cccc12</smiles>

4<smiles>O=C(O)c1c[nH]c2ccccc12</smiles>

5
Indolyl-3-lactic acid (3): $\mathrm{C}_{11} \mathrm{H}_{11} \mathrm{NO}_{3}$ (205.2), colorless, moderately polar, UV-absorbing solid $(12.8 \mathrm{mg})$, stained violet by anisaldehyde/sulphuric acid and heating. $-R_{\mathrm{f}}=0.35$ $\left(\mathrm{CHCl}_{3} / 5 \% \mathrm{MeOH}\right) .-{ }^{1} \mathrm{H} \mathrm{NMR}\left(\mathrm{CDCl}_{3}, 300 \mathrm{MHz}\right): \delta=10.75$ (s br, 1H, NH), 8.31 (s br, 1H, OH), 7.72 (dd, ${ }^{3} J=7.9 \mathrm{~Hz},{ }^{4} J=$ $1.1 \mathrm{~Hz}, 1 \mathrm{H}, 4-\mathrm{H}), 7.38\left(\mathrm{dd},{ }^{3} J=8.3 \mathrm{~Hz},{ }^{4} J=1.1 \mathrm{~Hz}, 1 \mathrm{H}, 7-\mathrm{H}\right)$, $7.20\left(\mathrm{td},{ }^{3} J=7.2 \mathrm{~Hz},{ }^{4} J=1.2 \mathrm{~Hz}, 1 \mathrm{H}, 5-\mathrm{H}\right), 7.10\left(\mathrm{td},{ }^{3} J=7.2\right.$ $\left.\mathrm{Hz},{ }^{4} J=1.1 \mathrm{~Hz}, 1 \mathrm{H}, 6-\mathrm{H}\right), 7.11\left(\mathrm{~d},{ }^{3} J=0.8 \mathrm{~Hz}, 1 \mathrm{H}, 2-\mathrm{H}\right), 4.55$ (m, 1H, 2'-H), $3.36\left(\mathrm{dd},{ }^{2} J_{\mathrm{AB}}=11.1 \mathrm{~Hz},{ }^{3} J_{\mathrm{AX}}=4.2 \mathrm{~Hz}, 1 \mathrm{H}, 2^{\prime}-\right.$ $\left.\mathrm{CH}_{\mathrm{A}}\right), 3.26\left(\mathrm{dd},{ }^{3} \mathrm{~J}=6.1 \mathrm{~Hz}, 1.1,1 \mathrm{H}, 2^{\prime}-\mathrm{CH}_{\mathrm{B}}\right) .-{ }^{1} \mathrm{H}$ NMR (DMSO- $\left.d_{6}, 300 \mathrm{MHz}\right): \delta=10.70(\mathrm{~s} \mathrm{br}, 1 \mathrm{H}, \mathrm{NH}), 7.55$ (dd, ${ }^{3} J=$ $\left.7.9 \mathrm{~Hz},{ }^{4} J=1.1 \mathrm{~Hz}, 1 \mathrm{H}, 4-\mathrm{H}\right), 7.32\left(\mathrm{dd},{ }^{3} J=8.3 \mathrm{~Hz},{ }^{4} J=1.1\right.$ $\mathrm{Hz}, 1 \mathrm{H}, 7-\mathrm{H}), 7.11$ (d, $\left.{ }^{3} J=0.8 \mathrm{~Hz}, 1 \mathrm{H}, 2-\mathrm{H}\right), 7.05\left(\mathrm{td},{ }^{3} J=7.2\right.$ $\left.\mathrm{Hz},{ }^{4} J=1.2 \mathrm{~Hz}, 1 \mathrm{H}, 5-\mathrm{H}\right), 6.92\left(\mathrm{td},{ }^{3} J=7.2 \mathrm{~Hz},{ }^{4} J=1.1 \mathrm{~Hz}\right.$, 1H, 6-H), 4.45 (s br, 1H, OH), 3.75 (m, 1H, 2'-H), 3.15 (dd, $\left.{ }^{2} J_{\mathrm{AB}}=11.1 \mathrm{~Hz},{ }^{3} J_{\mathrm{AX}}=4.2 \mathrm{~Hz}, 1 \mathrm{H}, 2^{\prime}-\mathrm{CH}_{\mathrm{A}}\right), 2.65\left(\mathrm{dd},{ }^{3} J=6.1\right.$ $\mathrm{Hz}, 1.1,1 \mathrm{H}, 2$ '- $\mathrm{CH}_{\mathrm{B}}$ ) (Figure 4). - EI MS (70 eV): $\mathrm{m} / \mathrm{z}(\%)=$ $205\left([\mathrm{M}]^{+.}, 18\right), 130\left([\mathrm{M}-(\mathrm{HO}-\mathrm{CH}-\mathrm{COOH})]^{+.}, 100\right)$ (Figure 5).

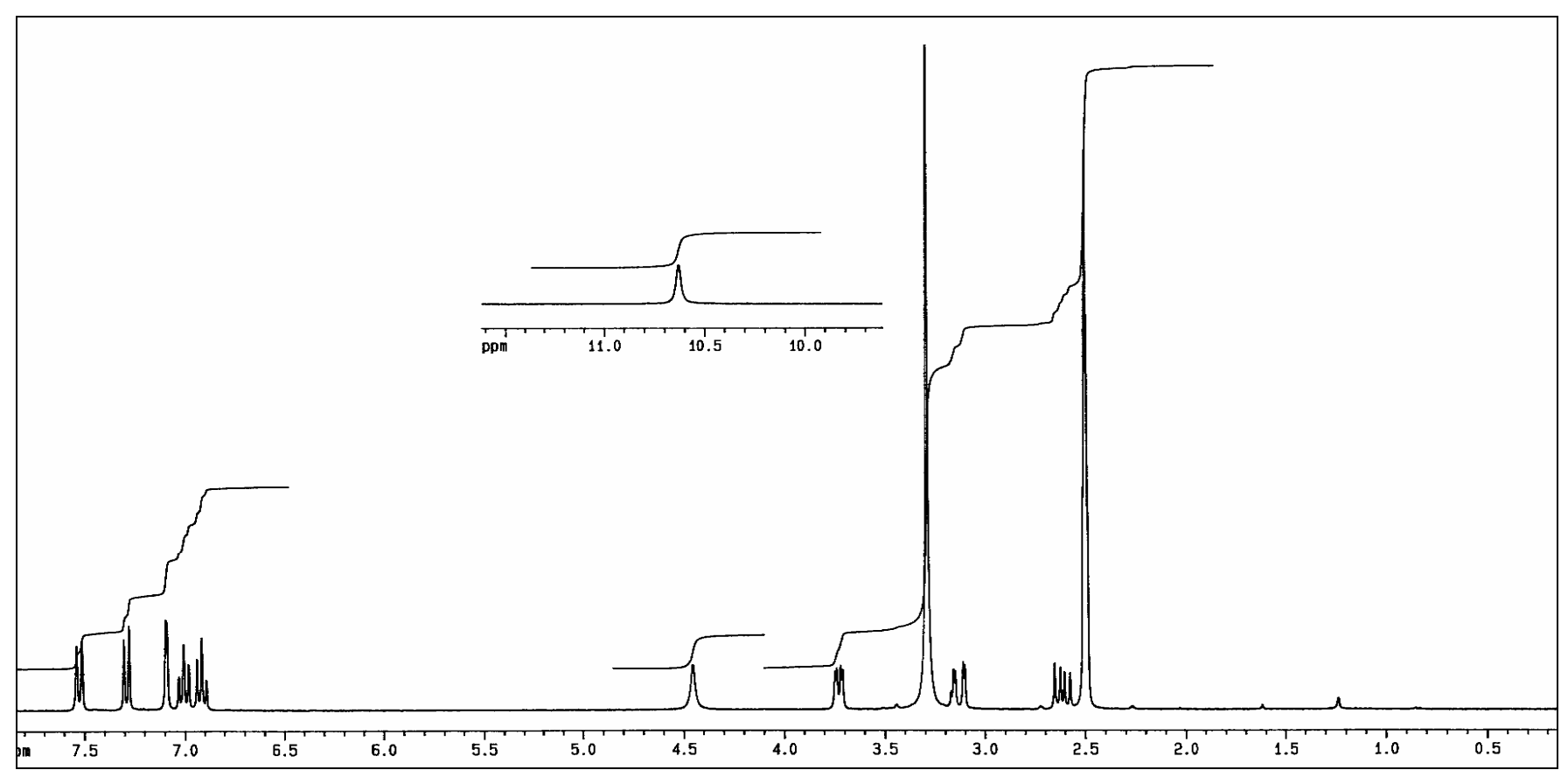

Figure 4. ${ }^{1} \mathrm{H}$ NMR (DMSO- $d_{6}, 300 \mathrm{MHz}$ ) of indolyl-3-lactic acid 


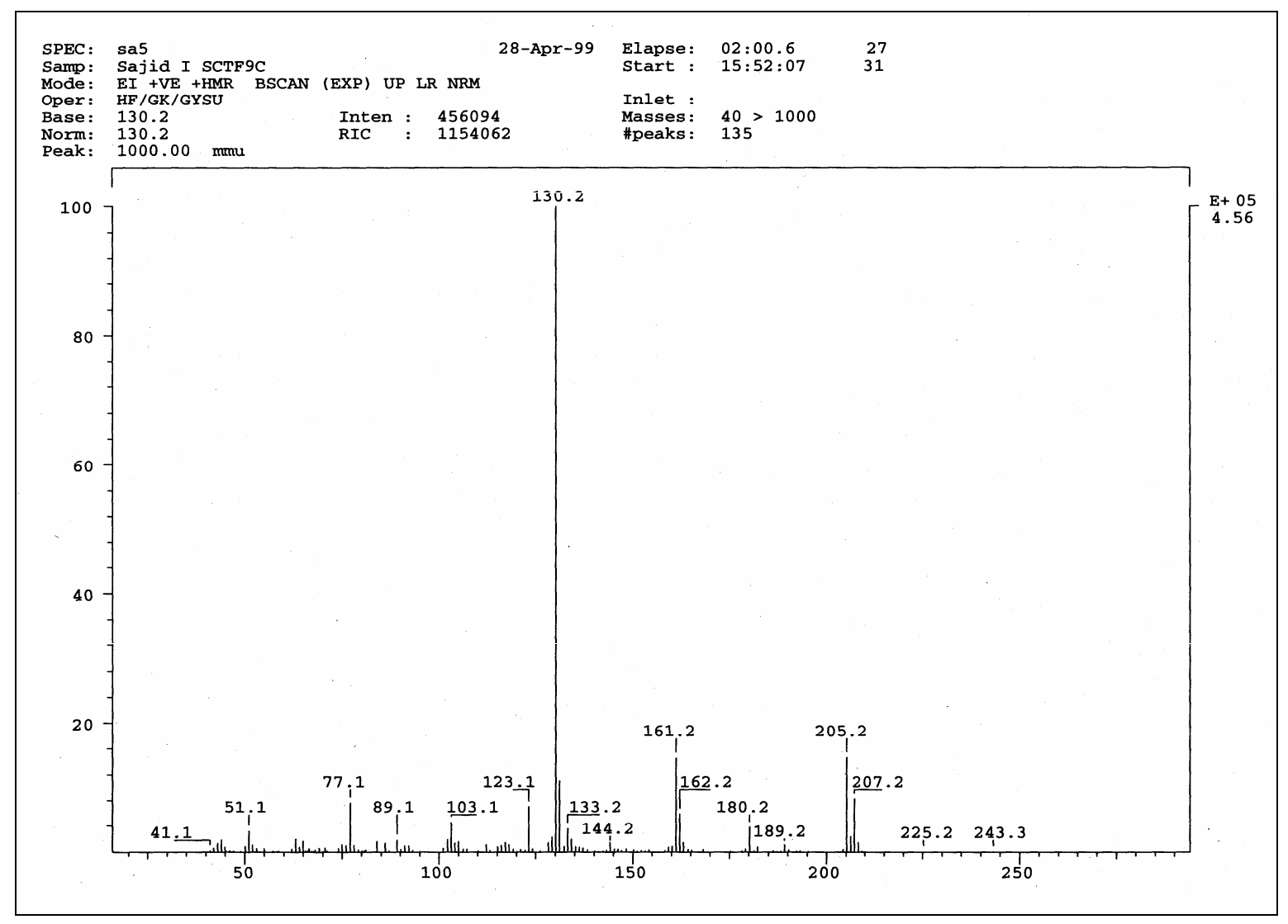

Figure 5. EI MS spectra of indolyl-3-lactic acid

Impact of different media compositions and culture conditions on the yield of the active metabolites produced by Streptomyces sp. CTF9

The different media compositions (A to F) exhibited significantly distinct impacts on the yield of the active metabolites of the isolate Streptomyces sp. CTF9. Under the $\mathrm{CC} 1$ culture conditions, the media $\mathrm{E}$ and $\mathrm{F}$ exhibited highly significant impacts on the yield of the metabolites, compared to the other culture media A, B, C and D (Table 1). Under the CC2 culture conditions, the medium D showed significant impact on the growth of CTF9, followed by the medium F, inducing the second highest yield. Under the CC3 culture conditions, the medium $\mathrm{F}$ showed the most significant increase in the weight of the crude extracts, in addition, a significant, but lesser, impact on the yield was also observed in the media $\mathrm{E}$ and D. Under the CC4 culture conditions, the medium D yielded the maximum quantity of the crude extracts, and the second highest yielding was the medium F, which yielded a significantly higher quantity of the crude extracts, compared to the media A, B, C and E (Table 1).

Similarly, different culture conditions (CC1 to $\mathrm{CC} 4)$ exhibited significantly different impacts on the growth of the strain Streptomyces sp. CTF9 and the yield of its active metabolites. In case of the media A and B, significant effects on the yield were observed under the CC4 culture conditions, compared to the other culture conditions, i.e., $\mathrm{CC} 1, \mathrm{CC} 2$ and CC3 (Table 1). In case of the medium $C$, the impacts of the $\mathrm{CC} 2$ and $\mathrm{CC} 4$ culture conditions were maximal and 
comparable but were significantly different from those of the other culture conditions. A significant increment in yield, to the maximum level, was obtained in the medium $\mathrm{D}$, when the strain was cultured under the $\mathrm{CC} 2$ conditions. The relative significance of the other three culture conditions, in terms of their effects on the yield in the medium D, was $\mathrm{CC} 4>\mathrm{CC} 3>\mathrm{CC} 1$. In case of the media $\mathrm{E}$ and $\mathrm{F}$, the $\mathrm{CC} 3$ conditions significantly increased the yield of the crude extracts, to the maximum level, compared to all the other culture conditions (CC1, CC2 and CC4; Table 1).

Table 1. Comparison of the weight of the crude extracts $/ 250 \mathrm{ml}$ culture broth of the strain CTF9 for six media compositions and four sets of culture conditions (expressed as the mean of three replicates \pm S.E)

\begin{tabular}{lllllll}
\hline \multirow{2}{*}{$\begin{array}{c}\text { Culture } \\
\text { conditions }\end{array}$} & \multicolumn{5}{c}{ Different media compositions } \\
\cline { 2 - 7 } & \multicolumn{7}{c}{ Med A } & Med B & Med C & Med D & Med E & Med F \\
\hline CC1 & $22.65^{\text {ey }}$ & $26.61^{\mathrm{dy}}$ & $25.75^{\mathrm{dx}}$ & $96.66^{\mathrm{cz}}$ & $166.68^{\mathrm{ax}}$ & $151.50^{\mathrm{by}}$ \\
& \pm 0.805 & \pm 0.352 & \pm 1.014 & \pm .0 .476 & \pm 0.644 & \pm 0.231 \\
CC2 & $32.593^{\mathrm{fx}}$ & $51.61^{\mathrm{cx}}$ & $34.41^{\mathrm{ew}}$ & $173.06^{\mathrm{aw}}$ & $37.32^{\mathrm{dy}}$ & $161.05^{\mathrm{bx}}$ \\
& \pm 1.273 & \pm 1.951 & \pm 0.231 & \pm 0.669 & \pm 1.544 & \pm 1.187 \\
CC3 & $13.793^{\mathrm{ez}}$ & $26.62^{\mathrm{dy}}$ & $26.61^{\mathrm{dx}}$ & $106.36^{\mathrm{cy}}$ & $171.63^{\mathrm{bw}}$ & $183.50^{\mathrm{aw}}$ \\
& \pm 0.453 & \pm 0.473 & \pm 0.929 & \pm 1.509 & \pm 0.918 & \pm 1.097 \\
CC4 & $64.27^{\mathrm{cw}}$ & $58.90^{\mathrm{dw}}$ & $36.55^{\mathrm{fw}}$ & $150.87^{\mathrm{ax}}$ & $40.08^{\mathrm{ey}}$ & $127.29^{\mathrm{bz}}$ \\
& \pm 0.274 & \pm 1.674 & \pm 0.199 & \pm 0.502 & \pm 1.319 & \pm 1.207 \\
\hline
\end{tabular}

Values designated by a, b, c, d, e, and $\mathrm{f}$ are for six different media compositions, Values designated by $\mathrm{w}, \mathrm{x}, \mathrm{y}$, and $\mathrm{z}$ are for four different culture conditions, Values designated with the same alphabets are not significantly different, Duncan's (1955) multiple range test at the significance level $=0.001$ (Med A: malt extract $10 \mathrm{~g}$, yeast extract $4 \mathrm{~g}$, and glucose $4 \mathrm{~g}$ in $1 \mathrm{~L}$ of $\mathrm{DH}_{2} \mathrm{O}$, Med B: soya been fat $20 \mathrm{~g}$ and mannitol $20 \mathrm{~g}$ in $1 \mathrm{~L}$ of $\mathrm{DH}_{2} \mathrm{O}$, Med C: glucose anhydrous $10 \mathrm{~g}$, peptone $2 \mathrm{~g}$, yeast extract $1 \mathrm{~g}$, and meat extract $1 \mathrm{~g}$ in $1 \mathrm{~L}$ of $\mathrm{DH}_{2} \mathrm{O}, \mathrm{Med} \mathrm{D}$ : yeast extract $40 \mathrm{~g}$, glucose $5 \mathrm{~g}$, and $\mathrm{CaCl}_{2} 45 \mathrm{~g}$ in $1 \mathrm{~L}$ of $\mathrm{DH}_{2} \mathrm{O}$, Med E: trypton $10 \mathrm{~g}$, yeast extract $5 \mathrm{~g}, \mathrm{NaCl} 10 \mathrm{~g}$, and glucose $5 \mathrm{~g}$ in $1 \mathrm{~L}$ of

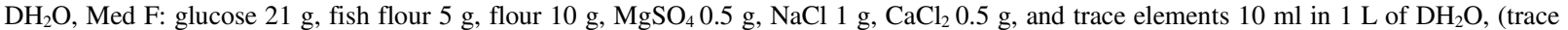
elements stock solution: $\mathrm{FeSO}_{4} 0.2 \mathrm{~g}, \mathrm{COCl}_{2} 0.04 \mathrm{~g}, \mathrm{CaCl}_{2} 0.04 \mathrm{~g}$, manganese(II) chloride $0.04 \mathrm{~g}$, zinc sulphate $0.08 \mathrm{~g}$, and sodium borate 0.08 $\mathrm{g}$ in $1 \mathrm{~L}$ of $\left.\mathrm{DH}_{2} \mathrm{O}\right)\left(\mathrm{CC} 1: \mathrm{pH} 6.5\right.$, the incubation temperature of $28^{\circ} \mathrm{C}$, shaking at $95 \mathrm{rpm}$, for 7 days $\mathrm{CC} 2: \mathrm{pH} 6.5$, the incubation temperature of $35^{\circ} \mathrm{C}$, shaking at $110 \mathrm{rpm}$, for 7 days $\mathrm{CC} 3$ : $\mathrm{pH} 7.8$, the incubation temperature of $28^{\circ} \mathrm{C}$, shaking at $95 \mathrm{rpm}$, for 7 days $\mathrm{CC} 4$ : $\mathrm{pH} 7.8$, the incubation temperature of $35^{\circ} \mathrm{C}$, shaking at $110 \mathrm{rpm}$, for 7 days)

\section{Impact of different media compositions and culture conditions on the antimicrobial activity of the strain Streptomyces sp. CTF9}

Antimicrobial activity of the extracts was determined using two fungal test strains (Candida albicans and Mucor miehei) to assess the relative concentration of the active metabolites in a crude extract. The different media compositions (A to $\mathrm{F}$ ) induced comparable antimicrobial responses in an individual set of culture conditions; however, minor variations were observed. In case of the $\mathrm{CC} 1$ culture conditions, the optimal response, in respect to antimicrobial activity, was observed in the crude extracts from the media B and D (Table 2). Under the CC2 culture condition, the medium E induced a significant antimicrobial activity against Candida albicans, whereas the medium $\mathrm{C}$ induced a significant antimicrobial activity against Mucor miehei. Under the CC3 culture conditions, the media $\mathrm{B}, \mathrm{D}$ and $\mathrm{F}$ induced the most significant antimicrobial activity against both test organisms. In case of the CC4 culture conditions, the optimal antimicrobial activity against both test organisms was seen in the crude extracts from the media $\mathrm{A}$ and $\mathrm{E}$ (Table 2).

Similarly, different culture conditions (CC1 to CC4) also induced comparable antimicrobial responses in a specific culture medium with slight deviations in some cases. In case of 
the medium $\mathrm{A}$, the $\mathrm{CC} 4$ and $\mathrm{CC} 2$ culture conditions showed significant impacts on the antimicrobial activity against both test organisms, compared to the $\mathrm{CC} 1$ and $\mathrm{CC} 3$ culture conditions (Table 2). In the medium B, the CC3 culture conditions showed a significant impact on the antimicrobial activity, compared to the other culture conditions. In the medium $\mathrm{C}$, the optimal antimicrobial response was observed under the $\mathrm{CC} 2$ culture conditions. In the medium $\mathrm{D}$, the culture conditions $\mathrm{CC} 1, \mathrm{CC} 2$ and $\mathrm{CC} 4$ showed comparable impacts on the antimicrobial activity against both test organisms; however, compared to $\mathrm{CC} 3$, the antimicrobial activity against Candida albicans was weaker, whereas the antimicrobial activity against Mucor miehei was stronger. In the medium E, the impacts of the culture conditions $\mathrm{CC} 4$ and $\mathrm{CC} 2$ on antimicrobial activity were comparable and were more significant, compared to those of $\mathrm{CC} 1$ and $\mathrm{CC} 3$, against both test organisms. In case of the medium $\mathrm{F}$, the extracts from the culture conditions $\mathrm{CC} 3$ and CC4 exhibited significantly higher antimicrobial activity against both test organisms, compared to those from $\mathrm{CC} 1$ and CC2 (Table 2).

Table 2. Comparison of the antimicrobial activity of the strain CTF9 at six media compositions and four sets of culture conditions (expressed as the mean of three replicates \pm S.E)

\begin{tabular}{|c|c|c|c|c|c|c|c|c|}
\hline \multirow{3}{*}{$\begin{array}{l}\text { Media / } \\
\text { Culture } \\
\text { conditions }\end{array}$} & \multicolumn{8}{|c|}{$\begin{array}{l}\text { Antimicrobial activity against test organisms } \\
\text { Zone of inhibition }(\mathrm{mm})\end{array}$} \\
\hline & \multicolumn{4}{|c|}{ Candida albicans } & \multicolumn{4}{|c|}{ Mucor miehei } \\
\hline & CC1 & $\mathrm{CC2}$ & $\mathrm{CC3}$ & $\mathrm{CC4}$ & CC1 & $\mathrm{CC2}$ & CC3 & $\mathrm{CC4}$ \\
\hline \multirow[t]{2}{*}{ Med A } & $0^{\mathrm{cy}}$ & $17.6^{\mathrm{bx}}$ & $0^{\mathrm{cy}}$ & $19.6^{\text {aw }}$ & $0^{\mathrm{dx}}$ & $12^{\mathrm{cw}}$ & $0^{\mathrm{dx}}$ & $13^{\text {aw }}$ \\
\hline & \pm 0.000 & \pm 0.333 & \pm 0.000 & \pm 0.333 & \pm 0.000 & \pm 0.577 & \pm 0.000 & \pm 0.000 \\
\hline \multirow[t]{2}{*}{ Med B } & $13^{\mathrm{ax}}$ & $0^{\mathrm{ez}}$ & $16.6^{\mathrm{aw}}$ & $11^{\mathrm{cy}}$ & $10.6^{\mathrm{bx}}$ & $0^{\text {dy }}$ & $12^{b w}$ & $11^{\mathrm{bx}}$ \\
\hline & \pm 0.000 & \pm 0.000 & \pm 0.333 & \pm 0.000 & \pm 0.333 & \pm 0.00 & \pm 0.000 & \pm 0.000 \\
\hline \multirow[t]{2}{*}{ Med C } & $0^{\mathrm{cx}}$ & $11.6^{\mathrm{cw}}$ & $0^{\mathrm{cx}}$ & $0^{\mathrm{dx}}$ & $0^{\text {dy }}$ & $14.6^{\mathrm{aw}}$ & $11^{\mathrm{cx}}$ & $0^{\mathrm{cy}}$ \\
\hline & \pm 0.000 & \pm 0.333 & \pm 0.000 & \pm 0.000 & \pm 0.000 & \pm 0.333 & \pm 0.000 & \pm 0.000 \\
\hline \multirow[t]{2}{*}{ Med D } & $11^{b x}$ & $10.6^{\mathrm{dx}}$ & $12^{\mathrm{bw}}$ & $11^{\mathrm{cx}}$ & $12.6^{\mathrm{aw}}$ & $13^{b w}$ & $11^{\mathrm{cx}}$ & $13^{\mathrm{aw}}$ \\
\hline & \pm 0.000 & \pm 0.333 & \pm 0.000 & \pm 0.000 & \pm 0.333 & \pm 0.000 & \pm 0.000 & \pm 0.000 \\
\hline \multirow[t]{2}{*}{ Med E } & $0^{\mathrm{cx}}$ & $19.6^{\mathrm{aw}}$ & $0^{\mathrm{cx}}$ & $20^{\text {aw }}$ & $9.6^{\mathrm{cx}}$ & $13^{b w}$ & $0^{\text {dy }}$ & $13^{\text {aw }}$ \\
\hline & \pm 0.000 & \pm 0.333 & \pm 0.000 & \pm 0.000 & \pm 0.333 & \pm 0.000 & \pm 0.000 & \pm 0.000 \\
\hline \multirow[t]{2}{*}{ Med F } & $0^{\mathrm{cy}}$ & $0^{\text {ey }}$ & $12.6^{\mathrm{bx}}$ & $16.6^{b w}$ & $0^{\mathrm{dy}}$ & $0^{\mathrm{dy}}$ & $15.6^{\text {aw }}$ & $11^{b x}$ \\
\hline & \pm 0.000 & \pm 0.000 & \pm 0.333 & \pm 0.333 & \pm 0.000 & \pm 0.000 & \pm 0.333 & \pm 0.000 \\
\hline \multicolumn{9}{|c|}{ 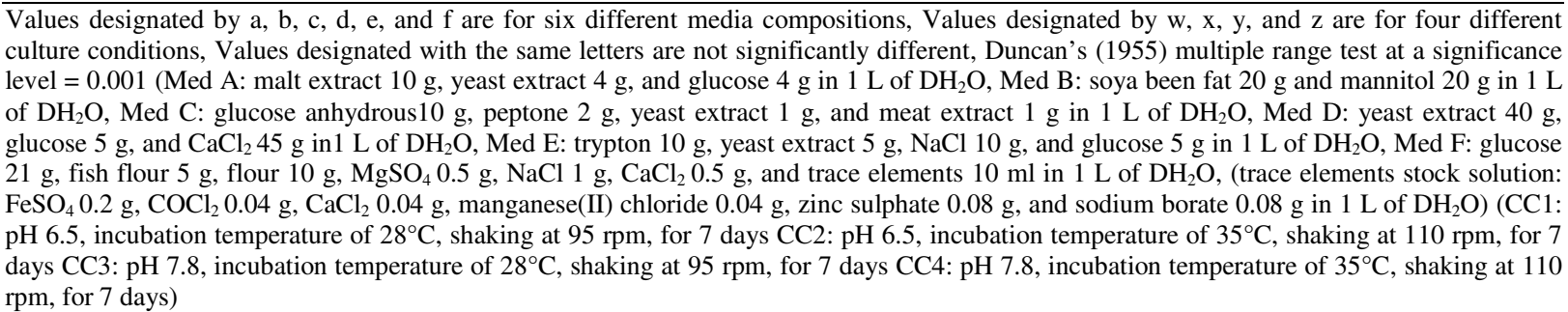 } \\
\hline
\end{tabular}

\section{DISCUSSION}

The present work describes the fermentation, isolation, purification and structure elucidation of the antifungal agents phenylacetic acid (1) and indolyl-3-lactic acid (3) from a newly isolated cotton field isolate Streptomyces sp. CTF9 in addition to the culture optimization to examine the appropriate medium components and culture conditions for the maximum yield of these commercially important compounds. Phenylacetic acid, a deamination product of phenylalanine, has been known for its pervasive applications in agriculture, pharmaceutical, and cosmetic industries. It has been known to exhibit a positive 
effect on the growth and development of different cereal crops (22). Wightman and Lighty (28) found that phenylacetic acid (1) acts as a natural auxin in the shoots of higher plants, such as barley, corn, tobacco, and tomato. The in vitro and in vivo antifungal activity of phenylacetic acid has been reported by many studies $(7,11,15)$, suggesting that it is a potential agroactive and biocontrol agent. In microbial antibiotic production, phenylacetic acid is added as a precursor to the culture of Penicillium chrysogenum to increase the production of penicillin G (9). Phenylacetic acid is also used in perfumes at low concentrations.

Indolyl compounds, including tryptophol (4) and indole-3carboxylic acid (5) (12, 27), are frequently isolated from bacteria and are characterized by their specific color reactions with anisaldehyde/sulphuric acid (violet) and Ehrlich's (orange) spraying reagents. Compound 5 is known as a fungal metabolite from Lasiodiplodia theobromae (1). From the newly isolated cotton field Streptomyces sp. CTF9, indolyl-3-lactic acid (3) (12.8 mg) was obtained as colorless solid, showing the same physico-chemical and chromatographic properties as 4 and 5. Compound 3 is often isolated from bacteria, fungi and yeast (14) and exhibits the antimicrobial activity against Candida albicans.

Streptomyces can grow on a variety of media and under different culture conditions; however, it is usually helpful to identify the optimal medium, temperature, $\mathrm{pH}$ and aeration of the interesting strains for large-scale cultivation. The nutrients and culture conditions play an important role in the onset and intensity of secondary metabolism. To achieve high product yields, it is a prerequisite to identify a proper production medium to be used for an efficient fermentation process (17). The medium composition is usually related to the biosynthesis of antibiotics (4). The role of the medium is to provide nutrients and precursors to the culture (5). Six media compositions (A, B, C, D, E, and F), along with four sets of culture conditions (CC1, CC2, CC3 and $\mathrm{CC} 4)$, were examined to determine the ability of the Streptomyces sp. CTF9 to use different carbon and nitrogen sources and to identify the optimal culture conditions for the maximum yields of phenylacetic acid and indolyl-3-lactic acid. The cultural optimization studies revealed that different media compositions and cultural conditions have significant impacts on the growth and antimicrobial activity of the strain CTF9: it exhibited promising growth on the culture media D, E and F; however, the maximum yields of the crude extracts were obtained from the medium D under the CC2 culture conditions (Table 1) and from the media $\mathrm{E}$ and $\mathrm{F}$ under the culture conditions $\mathrm{CC} 1$ and CC3 (Table 1). The similar impacts of different media on the growth demonstrate the ability of the strain CTF9 to use various nitrogen sources (including yeast extract, peptone, fish flour, etc.) and different carbon sources supplemented in these media. The impacts of other media, such as A, B and C, on the growth of the strain CTF9 was demonstrated by the low yield of the crude extracts, compared to those of the media D, E and F (Table 1). Different quantities of the crude extracts were obtained from the same medium under different culture conditions. In the media A, B, C and D, the culture conditions CC2 and CC4 showed significant impacts on the growth, compared to the culture conditions $\mathrm{CC} 1$ and $\mathrm{CC} 3$, whereas in the media $\mathrm{E}$ and $\mathrm{F}$, the culture conditions $\mathrm{CC} 1$ and $\mathrm{CC} 3$ showed a significant impact on the growth, compared to CC2 and CC4, indicating the ability of the strain CTF9 to grow in a broad range of temperatures $\left(28\right.$ to $\left.35^{\circ} \mathrm{C}\right)$ and $\mathrm{pH}$ values $(6.5$ to 7.8). Studies were also conducted on the antimicrobial activity of the crude extracts of the strain CTF9, obtained from different media under different culture conditions, against the test organisms Candida albicans and Mucor miehei. In general, different media and culture conditions induced similar activities against the test organisms with minor variations, suggesting that the proportion of the active components in the unit weight of the crude extracts is similar. Based on the extensive investigations on different media compositions and culture conditions, we demonstrate that the maximum yield of the antifungal metabolites produced by the strain CTF9 
(phenylacetic acid and indolyl-3-lactic acid) can be obtained by culturing the strain on the media $\mathrm{D}, \mathrm{E}$ or $\mathrm{F}$, at $35^{\circ} \mathrm{C}$ and $\mathrm{pH} 7.8$.

\section{ACKNOWLEDGMENTS}

We thank Prof. Dr Hartmut Laatsch (Institute of Organic and Biomolecular Chemistry, University of Gottingen, Germany) for providing the facilities for fermentation, MS and NMR analysis. The financial support of this work by a grant from the Higher Education Commission (HEC) of Pakistan under IRSIP is gratefully acknowledged.

\section{REFERENCES}

1. Aldridge, D.C.; Galt, M.S.; Giles, D.; Turner, W.B. (1971). Metabolites of Lasiodiplodia theobromae. J. Chem. Soc., C, 1623-1627.

2. Ayer, W.A.; Trifonov, L.S. (1995). Phenolic and polyketide metabolites of the aspen blue stain fungus Ophiostoma crassivaginata. Phytochemistry., 38, 371-372.

3. Berdy, J. (2005). Bioactive microbial metabolites: A personal view. J. Antibiot., 58(1), 1-26.

4. Chatterjee, S.; Vining, L.C. (1981). Nutrient utilization in actinomycetes: Induction of $\alpha$-glucosidases in Streptomyces venezualae. Can. J. Microbiol., 27, 639-645.

5. Demain, A.L.; Aharonowitz, Y.; Martin, J.F. (1983). Metabolic control of secondary biosynthetic pathways, In: Vining, L.C. (ed). Biochemistry and genetic regulation of commercially important antibiotics, AddisonWesley, Reading. p. 49-71.

6. Hayakawa, M.; Ishizawa, K.; Nonomura, H. (1988). Distribution of rare actinomycetes in Japanese soils. J. Ferment. Technol., 66, 367-373.

7. Hwang, B.K; Lim, S.W.; Kim, B.S.; Lee, J.Y.; Moon, S.S. (2001). Isolation and In Vivo and In Vitro Antifungal Activity of Phenylacetic Acid and Sodium Phenylacetate from Streptomyces humidus. Appl. Environ. Microbiol. 67, 3739-3745.

8. Jiang, C.L.; Xu, L.H. (1996). Diversity of aquatic actinomycetes in lakes of the middle plateau, Yunnan, China. Appl. Environ. Microbiol., 62, 249-253.

9. Kato, K. (1953). Further notes on penicillin-nucleus. J. Antibiot., 4, 184185.

10. Kato, K. (1953). Occurrence of penicillin-nucleus in culture broths. $J$. Antibiot., 6, 130-136.

11. Kim, B.S.; Lee, J.Y.; Hwang, B.K. (1998). Diversity of actinomycetes antagonistic to plant pathogenic fungi in cave and sea-mud soils of Korea. J. Microbiol., 36, 86-92.
12. Kradolfer, P.; Niederberger, P.; Huetter, R. (1982). Tryptophan degradation in Saccharomyces cerevisiae: characterization of two aromatic aminotransferases. Arch. Microbiol. 133, 242-248.

13. Kuang-Ren, C.; Turksen, S.; Umran, E.; Timmer, L. W.; Ueng, P. P. (2003). Indole derivatives produced by the fungus Colletotrichum acutatum causing lime anthracnose and post bloom fruit drop of citrus. FEMS Microbiol. Letters., 226, 23-30.

14. Laatsch, H. (2007). AntiBase 2007, A Data Base for Rapid Structural Determination of Microbial Natural Products, 2007 and annual updates, Chemical Concepts, Weinheim, Germany; see http://wwwuser. gwdg. de/ ucoc/laatsch/AntiBase. htm.

15. Lee, J.Y.; Kim, H.S.; Kim, K.D.; Hwang, B.K. (2004). In Vitro AntiOomycete Activity and In Vivo Control Efficacy of Phenylacetic Acid Against Phytophthora capsici. Plant Pathol. J., 20, 177-183.

16. Lu, C.G.; Liu, W.C.; Qiu, J.Y.; Wang, H.M.; Liu, T.; Liu, D.W. (2008). Identification of an antifungal metabolite produced by a potential biocontrol actinomyces strain A01. Braz. J. Microbiol., 39, 701-707.

17. Macedo, J.A.; Sette, L.D.; Sato, H.H. (2007). Optimization of medium composition for transglutaminase production by a Brazilian soil Streptomyces sp. Electr. J. Biotechnol., 10 (4), 618-626.

18. Miyadoh, S. (1993). Research on antibiotic screening in Japan over the last decade: a producing microorganisms approach. Actinomycetol., 9, 100-106.

19. Nair, M. G.; Burke, B. A. (1988). A new fatty acid methyl ester and other biologically active compounds from Aspergillus niger. Phytochemistry, 27, 3169-73.

20. Power, F.B.; Browning, H.J. (1912). Constituents of Taraxacum Root. J. Chem. Soc., 101, 2411-2429.

21. Sajid, I.; Yao, C.B.; Shaaban, K.A.; Hasnain, S.; Laatsch, H. (2009). Antifungal and antibacterial activities of indigenous Streptomyces isolates from saline farmlands: prescreening, ribotyping and metabolic diversity. World J. Microbiol. Biotechnol., 25, 601-610.

22. Sarwar, M.; Frankenberger, W.T. (1995). Fate of L-phenylalanine in soil and its effect on plant growth. Soil Sci., 59, 1625-1630.

23. Shomura, T. (1993). Screening for new products of new species of Dactylosporangium and other actinomycetes. Actinomycetol., 7, 88-98.

24. Soares A. C. F.; Sousa C. D. S.; Garrido M. D. S.; Perez J. O.; Almeida N. S. (2006). Soil streptomycetes with in vitro activity against the Yam pathogens Curvularia eragrostides and Colletotrichum gloeosporioides. Braz. J. Microbiol. 37:456-461.

25. Suzuki, K.; Nagai, K.; Shimizu,Y.; Suzuki, Y. (1994). Search for actinomycetes in screening for new bioactive compounds. Actinomycetol., 8, 122-127.

26. Tanaka, Y.T.; Omura, S. (1993). Agroactive compounds of microbial origin. Аnпu. Rev. Microbiol., 47:57-87. 
Sajid, I. et al.

27. Turner, W. B.; Aldridge, D. C.; Galt, M.; Giles, D. (1971). Metabolites of Lasiodiplodia theobromae . J. Chem. Soc. (C), 1623-1627.

28. Wightman, F.; Lighty, D.L. (1982). Identification of phenylacetic acid as
Antifungal metabolites from the Streptomyces

a natural auxin in the shoot of higher plants. Physiol, Plant., 55, 17-24.

29. Xu, L.H.; Li, Q.R.; Jiang, C.L. (1996). Diversity of soil actinomycetes in

Yunnan, China. Appl. Environ. Microbiol., 62, 244-248. 